\title{
Impatience and Credit Behavior: Evidence from a Field Experiment
}

\section{Abstract:}

Stephan Meier and Charles Sprenger

This paper tests whether heterogeneity of time preferences can explain individual credit behavior. In a field experiment targeting individuals from low-to-moderate income households, we measure individual time preferences through choice experiments, and then match these time preference measures to individual credit reports and annual tax returns.

We find that, controlling for disposable income and other individual characteristics, individuals who are less patient have lower credit scores and higher default rates. Moreover, people with dynamically inconsistent (quasi-hyperbolic) preferences have higher active borrowing levels.

Keywords: time preferences, credit behavior, credit scores, delinquencies, field experiment JEL codes: D12, D14, D91, C93

Stephan Meier is a senior economist at the Federal Reserve Bank of Boston's Research Center for Behavioral Economics and Decision-Making. His e-mail address is stephan.meier@bos.frb.org. Charles Sprenger is a Research Associate at the Federal Reserve Bank of Boston. His email address is charles.sprenger@bos.frb.org.

This paper, which may be revised, is available on the web site of the Federal Reserve Bank of Boston at http://www.bos.frb.org/economic/wp/index.htm.

We are grateful to Christine Benesch, Mary Burke, Jeff Carpenter, Chris Foote, Lorenz Goette, Fabià Gumbau-Brisa, Glenn Harrison, David Huffman, Elif Incekara, Cathleen Johnson, Jane Katz, Borja Larrain, Felix Oberholzer-Gee, Tanya Rosenblat, Julio Rotemberg, Jeremy Tobacman, Tyler Williams, and participants at the 2005 Economic Science Association meeting in Tucson and at conferences held by the Federal Reserve Bank of Boston and the University of Lausanne for helpful comments. Special thanks to Marques Benton (Department of Public and Community Affairs, Federal Reserve Bank of Boston) and Ralph Moore (Federal Reserve Bank of Boston Employee Credit Union), who made the study possible.

The views expressed herein are solely those of the authors and not those of the Federal Reserve System or the Federal Reserve Bank of Boston.

This version: March 2007

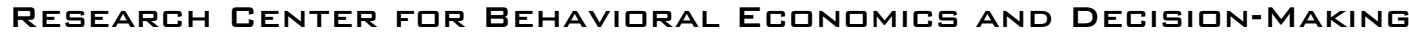


Many people have large amounts of debt. In the United States, households carry, on average, non-mortgage debt burdens of $\$ 12,900$, almost 20 percent of which is unsecured debt on credit cards. In the last decade, the median debt burden for credit card borrowers increased by 100 percent in nominal terms, rising from \$1,100 in 1995 to \$2,200 in 2004 (Bucks, Kennickell, Moore, 2006; Kennickell, Starr-McCluer, Sundén, 1997). In line with this growth is an increase in the number of people seeking credit counseling - a possible indication that many individuals see their own level of debt as suboptimal. ${ }^{1}$

One explanation for the credit problems apparent today is that individuals are hit by unexpected shocks (for example, medical expenses or unemployment spells). A critical implication of this view is that individual income and asset conditions should be the main factors determining whether a person will, ceteris paribus, cope with shock-related expenses or have problems servicing their outstanding debts (see Warren, 2004).

This paper tests an alternative view, namely that the heterogeneity of individual time preferences can explain differences in credit behavior. Credit behavior, borrowing and servicing debts, involves choices over time, and so is influenced by an individual's degree of impatience. A time preference theory of credit utilization allows for systematic suboptimal borrowing if individuals' preferences are time inconsistent. Dynamic inconsistency is modeled as present-biased time preferences, wherein individuals impose a lower discount factor ${ }^{2}$ between today and one period from today than between two subsequent periods in the future. An elegant formulation of such time preferences assumes a quasi-hyperbolic structure (for example Laibson, 1997; O'Donoghue and Rabin, 1999), leading to the following discounted utility from present activities in period $t$ and future activities in periods $t+1$ to $T$-t:

$$
U=u_{t}+\beta \sum_{i=1}^{T-t} \delta^{i} u_{t+i}
$$

1 The National Foundation for Credit Counseling (NFCC) doubled its volume through the 1990s, counseling 400,000 new individuals in 1990 and 880,000 in 2000. Notably this increase happened before changes in bankruptcy law required credit counseling as a precursor to Chapter 7 bankruptcy. Between 2 and 2.5 million individuals overall seek credit counseling each year (see Staten, Elliehausen, and Lundquist, 2002).

${ }^{2}$ In this paper, we will use individual discount factor (IDF) instead of individual discount rate (IDR) as a measure for individuals' time preferences; IDF $=1 /(1+\mathrm{IDR})$. 
Individuals exhibit a discount factor $\beta \delta$ between the present and a future period, but exhibit only a discount factor $\delta$ between two subsequent periods in the future. In these models, $\beta$ represents the present bias and $\delta$ the long-run discount factor. If $\beta=1$, individuals discount exponentially and the quasi-hyperbolic model reduces to standard exponential discounting. If $\beta<1$, individuals exhibit dynamic inconsistencies, discounting differently over time. Dynamic inconsistency strongly weights the value of present consumption, and so may lead individuals to borrow more for consumption in the present than they would ultimately like to borrow, given their long-run discount factors.

In the behavioral economics literature, dynamic inconsistency and resulting self-control problems are often stressed as an explanation of heterogeneity in credit usage (for example, Fehr, 2002). Yet there has been very little direct empirical evidence (discussed in detail in section II.2) to support this contention. Previous research has looked either at aggregate or selfreported debt measures. This is the first study that uses objective data from individual credit reports to analyze the effect of heterogeneity in long-run discount factors $\delta$ and present bias parameters $\beta$ on individual differences in credit behavior. We conduct an incentive-compatible choice experiment with a targeted group of low-to-moderate income individuals to measure each person's discount factor and present bias. These individual measures are then correlated with objective information on borrowing, delinquencies, and defaults obtained from credit reports. ${ }^{3}$

We find that an individual's long-run discount factor $(\delta)$ and degree of present bias $(\beta)$ are important determinants of individual credit behavior. First, individuals with higher present bias (lower $\beta$ ) have higher borrowing levels on active installment accounts (for instance, loans to finance car and furniture purchases) and on revolving accounts (mainly credit cards), even after controlling for disposable income and other socio-demographic characteristics. This finding suggests that individuals borrow more in the present than they actually would prefer to borrow given their long-term objectives. Second, the decision to

\footnotetext{
${ }^{3}$ In the United States credit reports contain extensive quantitative information provided by lenders on a
} person's credit behavior (Avery et al., 2003). 
default on accumulated debts is unrelated to individual differences in the degree of present bias. The decision not to pay back loans on time is, to a large degree, determined by an individual's long-run discount factor, $\delta$. Finally, as a consequence of the previous two findings on borrowing and repaying, we show that Fair Issac Corporation (FICO) credit scores, which reflect an individual's creditworthiness and are widely used to determine loan interest rates, are associated with long-run discount factors but not with present bias preferences. ${ }^{4}$ None of these results are driven by credit constraints, as our results are robust to both precise income and credit availability controls.

The two decisions involved in credit behavior, borrowing and then deciding whether to repay the loan, seem to be affected differently by an individual's discounting parameters, $\beta$ and $\delta$. We discuss an extension of the quasi-hyperbolic discounting model which can account for this difference. We suggest that an individual's affective decision making processes, which are those responsible for any present bias, are activated differently in the two decision environments (see Loewenstein and O'Donoghue, 2004). Whereas affective processes are likely to be activated in the borrowing decision environment, they may not play a role in the repaying decision environment. This critical difference could explain our results.

The paper proceeds as follows: section II presents conceptual considerations regarding impatience and credit behavior, and surveys existing empirical efforts to understand the relationship between time preferences and credit outcomes. Section III discusses our field experiment, our methodology for eliciting time preferences, and the data. Section IV presents the results. Section V discusses the importance of extending the quasi-hyperbolic model with insights on affective decision making. Section VI concludes.

${ }^{4}$ Credit scores can be used to determine not only the price (interest) of a loan but also for pricing insurance. Additionally, credit scores can be used by potential employers and landlords in employment and tenancy decisions. 


\section{Conceptual Considerations and Previous Empirical Research}

\section{II.1 Conceptual considerations}

Individuals make two decisions with respect to their credit behavior that are of interest for this paper. Individuals must first decide how much to borrow today from their future income streams; for example, individuals must decide first whether to buy a consumer good and then, conditional upon its purchase, whether the good should be paid for in full or financed over time. In the case of financing, individuals must then further decide whether and how to service their debts; for example, they must decide between paying bills and not paying bills with the accompanying potential for future delinquency penalties. As both the borrowing and servicing decisions involve intertemporal substitution, these choices are influenced by how an individual values the future compared to the present. ${ }^{5}$ Individuals who are more impatient and discount exponentially (and are therefore time consistent), are expected to borrow more in the present. As these individuals also have a low present value for the future option to borrow, they are correspondingly expected to be more likely to default on a repayment obligation.

Contrary to the exponential reading of time preferences, there are a number of studies showing that many individuals do not discount exponentially, but instead exhibit time preferences biased towards the present (see, for instance, Frederick, Lowenstein, and O'Donoghue, 2002). Additionally, evidence suggests that individuals differ substantially in their degree of present bias (see Coller, Harrison and Rutström 2005). Conceptually, presentbiased time preferences are synonymous with dynamic inconsistency, when individuals impose a lower discount factor between today and tomorrow than between two sequential days in the future. This differential discounting leads to a self-control problem. Individuals may make long-run plans for future periods, but they systematically violate these plans when these future

5 There exists a larger literature in psychology on the determinants of individual differences in impatience. Individual differences seem to be quite stable, as impatience in young children is strongly related to their behavior when they are older (see Mischel, Shoda, and Rodriquez, 1989). For a more recent economics-based study on impatience in children, see Bettinger and Slonim (2006). 
periods actually become the present (see Strotz, 1956). ${ }^{6}$ An elegant and simple way to account for differential discounting is to assume a quasi-hyperbolic discounting function, $U=u_{t}+\beta \sum_{i=1}^{T-t} \delta^{i} u_{t+i}$, as in Laibson (1997) or O'Donoghue and Rabin (1999). In these models $\beta$ represents the present bias, and $\delta$ represents the long-run discount factor. An individual discounts between today and tomorrow with $\beta \delta$, but discounts between two sequential days in the future with $\delta$ alone. Such a disjointed discounting function accounts for dynamic inconsistency.

With two discounting parameters, $\beta$ and $\delta$, the relationships between time preferences and credit behavior are more nuanced. An individual's long-run discount factor, $\delta$, is expected to affect borrowing and repayment behavior following the standard intuition: a lower $\delta$ should result in higher borrowing and a lower repayment rate. In theory, present bias, $\beta$, should yield similar effects with lower $\beta$ resulting in higher borrowing and lower levels of repayment.

For the borrowing decision, present-biased individuals may borrow more today, ceteris paribus, than individuals who have time-consistent preferences. The intuition is as follows: two individuals with exactly the same long-run discount factor should borrow the same amount, all else equal. If one of these individuals exhibits present bias, future time periods are further discounted, increasing that individual's relative value of present consumption over future consumption and decreasing the present value of the financing cost that will be borne in the future. Attractive financing terms and a preference for immediate gratification lead to increased borrowing behavior. Here, a lower $\beta$ results, ceteris paribus, in more borrowing (see Laibson, Repetto, and Tobacman, 2003; O'Donoghue and Rabin, 2005; and Shui and Ausubel, 2005). As a

\footnotetext{
${ }^{6}$ In 1930, this phenomenon was already apparent to Irving Fisher. In The Theory of Interest (1930: II.IV.53) Fisher notes that "personal differences [in impatience] are caused by differences in at least six personal characteristics: (1) foresight, (2) self-control, (3) habit, (4) expectations of life, (5) concern for the lives of other persons, (6) fashion." Thaler (1997) indicates that Fisher saw many of these personal characteristics as irrational and as leading to deviations from the standard time-consistent model in economics.
} 
result of the dynamic inconsistency, the level of borrowing will be too high according to an individual's own long-term perspective. ${ }^{7}$

The effect of dynamic inconsistency on the decision to repay should as well follow standard intuition. The likelihood of default may be correlated with an individual's present bias, as the same decision-making mechanism that leads an individual to over-borrow may lead him to procrastinate when faced with making the minimum required payment on a credit card bill. Furthermore, if a present-biased individual understands that she will also over-borrow in the future, she may want to restrict future adverse activities by defaulting, effectively committing her future self to acquiring zero debt. ${ }^{8}$

The reasoning above assumes that the present bias, $\beta$, is important for every intertemporal decision such as borrowing and repayment. Dynamic inconsistency is frequently modeled as the interplay between two separate cognitive decision-making systems: the affective system, which values immediate gratification and sharply discounts all future periods; and the deliberative system, which makes long-run plans and displays higher discount factors (see McClure et al., 2004). ${ }^{9}$ To say that $\beta$ is important in every intertemporal decision is to imply that the affective system responsible for present bias is activated in every time-related trade-off. In Section V we discuss an extension of the quasi-hyperbolic model by Loewenstein and O'Donoghue (2004), which allows for different stimuli to the affective system and hence

\footnotetext{
7 Without a commitment device, dynamically inconsistent individuals will always violate their long-term borrowing plans when the future becomes the present. Here naïveté is assumed. Under this assumption, present-biased individuals do not think that they will be present-biased in future time periods (see O'Donoghue and Rabin 1999). Making the individual more sophisticated complicates the intuition. Sophisticated present-biased consumers understand that they will also be present-biased in future time periods. They may make decisions to restrict the behavior of future selves to assure that the consumption path chosen in the first period is maintained. If these restrictions involve reducing current consumption, then it is not clear that increased borrowing should be related to present bias. If these restrictions can be made without sacrificing current consumption, through fixed repayment plans, for example, or if restrictions cannot be imposed due to a lack of commitment devices, increased borrowing should still be associated with present bias.

8 This assumes that default information is shared between lenders and that lenders don't loan to an individual who has previously defaulted.

9 This notion is captured in a number of two-system models of decision making (for example, Bernheim and Rangel, 2004; Bertaut and Haliassos, 2002; Fudenberg and Levine, 2006; Loewenstein and O'Donoghue, 2004; Shefrin and Thaler, 1988).
} 
different levels of relevance for $\beta$, depending on the intertemporal decision in question. Applying this extension to credit behavior gives predictions about the effect of $\beta$ on borrowing and repayment decisions which are more in line with our empirical results.

\section{II.2 Previous empirical research}

Previous empirical research on time preferences and credit behavior has mainly taken one of two paths. First, field studies analyzing aggregate credit and consumption outcomes present indirect evidence that a quasi-hyperbolic model predicts behavior better than an exponential model. Laibson, Repetto, and Tobacman (2005) estimate individual discount rates from aggregate credit card borrowing and conclude that a constant discount rate, as posited by exponential models, cannot account for the borrowing patterns seen in the data. Shui and Ausubel (2005) analyze a large-scale experiment in the credit card market and show that a model with quasi-hyperbolic time preferences is better able to predict why consumers react strongly to introductory offers with short-term, low-to-no interest "teaser rates." Based on their actual borrowing behavior, Shui and Ausubel calculate that individuals would ultimately pay less interest if they had chosen a contract with a higher initial interest rate but of a longer duration, as opposed to the short-term low teaser rate followed by a much higher subsequent interest rate. ${ }^{10}$

The second approach measures individual time preferences directly (often experimentally), and correlates these to self-reported individual credit balances or self-reported spending problems. Measuring individual discount factors in a field experiment in Denmark, Harrison et al. (2002) present results on whether people who report having a balance on a line of credit or credit card exhibit lower individual discount factors. Their study does not find a correlation between individual discount factors and self-reported credit card balances; however, this experiment was not designed to measure individuals' present bias in a quasihyperbolic model, as none of their choice experiment options involves present payoffs. Dohmen

${ }^{10}$ Other studies that test the validity of quasi-hyperbolic models analyze aggregate outcomes in food intake (Shapiro, 2005), in fitness center attendance (DellaVigna and Malmendier, 2006), in welfare program take-up (Fang and Silverman, 2006), in television watching (Benesch, Frey, and Stutzer, 2006), and in smoking behavior (Gruber and Köszegi, 2001). 
et al. (2006) show that their measure of time preferences and, in particular, their measure of dynamic inconsistency can explain whether individuals report having financial self-control problems. Specifically, they find that individuals who exhibit dynamic inconsistency report having more self-control problems in spending, a result that they interpret as indicating that dynamic inconsistency leads, ceteris paribus, to more borrowing than is optimal. ${ }^{11}$ Because the accuracy of self-reported measures of credit problems is particularly difficult to assess, as people generally underreport their debt levels by a factor of three (for example, see Gross and Souleles, 2002), we analyze objective data from credit reports on individual borrowing and default behavior.

While evidence is scarce on how impatience impacts upon the decision to borrow, to our knowledge there is no evidence exploring the relationship between actual (as opposed to reported) repayment behavior and impatience.

Our approach in this paper combines the two previous paths of research on heterogeneous time preferences and borrowing, and extends it with an analysis of impatience and repayment behavior. Using incentive-compatible choice experiments, we are able to directly calculate individual discount factors. Most importantly, we then match time preference information to objective credit outcomes provided by a credit reporting agency. Using time preference and credit report data in conjunction with socio-demographic variables, we are able to directly explore the relationship between time preferences and credit outcomes, controlling for socio-demographic effects. The next section presents the design of our field experiment and discusses our methodology.

\section{Credit Data and Design of Field Experiment}

The field experiment was conducted in Dorchester, a neighborhood in Boston, Massachusetts, at a Volunteer Income Tax Assistance (VITA) site designed to help local low-to-moderate

\footnotetext{
11 Other studies show that proxies for individual time preferences are correlated, for example, with uptake of a saving commitment device (Ashraf, Karlan, and Yin, 2006), job search behavior (DellaVigna and Paserman, 2005), and occupational choices (Munasinghe and Sicherman, 2005).
} 
income (LMI) tax filers. ${ }^{12}$ We recruited 155 individuals from LMI households to participate in the study while waiting for tax assistance. This non-standard subject pool is of particular interest for the research question at hand, as there are very few experimental studies focusing solely on the behavior of LMI families in developed countries. ${ }^{13}$ LMI families may or may not be significantly different from wealthy families in their preferences, but their less secure position puts them at great financial risk to health and income shocks (see Bertrand, Mullainathan, and Shafir, 2004). Though results based on focusing on LMI families may not be broadly applicable to an entire populace, the behavior exhibited by this cohort sheds light on the general relationship between impatience and credit behavior.

The 155 study participants have little disposable income, averaging around $\$ 17,400$ per year. Disposable income is calculated from individual tax returns as the addition of adjusted gross income and post-tax government transfers, such as the Massachusetts state tax refund and the federal tax refund. ${ }^{14}$ The majority of participants were African-American women, who were around 33 years old, had no education beyond high school, and had less than one dependent (see Panel A of Table 1 for summary statistics). These socio-demographic characteristics are controlled for in our analysis to address possible confounding correlations between sociodemographic status and both time preferences and credit behavior.

In order to test our hypothesis that the heterogeneity of time preferences leads to differences in credit behavior, all participants revealed their time preferences in a choice experiment and gave us permission to match this information to their credit reports for analysis.

12 There are currently 22 VITA sites in and around Boston, MA. Coordinated by a city-wide coalition of government and business leaders, VITA sites provide free tax preparation assistance to LMI households. Taxes are prepared by volunteers throughout tax season, from late-January to mid-April each year.

${ }_{13}$ An exception is Eckel, Johnson, and Montmarquette (2005), who analyze whether time preferences explain decisions in retirement savings for a sample of working poor individuals in Canada.

${ }^{14}$ We obtained income information for 145 individuals. The ten remaining individuals either did not file taxes at a VITA site in Greater Boston or did not have to file taxes due to their income level. For these individuals we impute their income as zero (the adjusted gross income and total refund of a non taxfiler) and control for any bias contributed by these observations in our analysis. All results are robust to the exclusion of individuals with missing information (see robustness tests in section IV.4). 


\section{III.1. Data on credit behavior}

Information on individual credit behavior comes from TransUnion \& Co., one of three major credit bureaus in the United States. TransUnion lists detailed information on credit behavior on each individual's credit history. In particular, credit reports reveal outstanding balances, how much of the available credit limit is utilized (and therefore whether people are credit constrained), past due balances, whether accounts are in debt collection, and whether people have had any adverse financial public records such as bankruptcy or court orders to pay. The accounts are divided into mortgages, installment plans, revolving accounts (which are predominately credit card accounts), and accounts closed by the credit grantor with remaining balances (Avery et al., 2003). All in all, unlike self-reported data, credit reports give a very detailed, objective picture of individual credit behavior.

Summary statistics of participants' credit behavior are reported in Panel B of Table 1. The average non-mortgage debt level on all active accounts in our sample is $\$ 8,557$ (s.d. $\$ 20,697) .{ }^{15}$ Average credit card debt is $\$ 1,160$ (s.d. $\$ 2,328$ ) yielding an average credit card debtto-income ratio of around 7 percent and a non-mortgage active account debt-to-income ratio of approximately 54 percent for the individuals with disposable incomes greater than zero $(\mathrm{n}=$ 144). Relative to the general population, our sample has notably high debt levels. According to the Survey of Consumer Finances, the average U.S. resident has a self-reported credit card debtto-income ratio of 4.3 percent and a non-mortgage debt-to-income ratio of 23.5 percent (authors' calculations based on Bucks, Kennickell, and Moore, 2006). Payments that are past due or have gone to collection show that some of the participants are unable or unwilling to service these debt levels. Average past-due payments on active accounts are $\$ 44$ (s.d. \$204), while the

${ }^{15}$ LMI populations frequently resort to non-traditional loan products when seeking credit. For a subset of our sample $(n=131)$, we use self-reported information on loans obtained from pawn brokers, check cashers, payday lenders, friends, and family. The participants also report whether they have any outstanding balances on bills due to medical providers, landlords, and utilities providers. Nontraditional debt of this type is relatively small, averaging $\$ 372$ (\$827) per person. Adding nontraditional debt to aggregate debt does not influence the results. As people often under-report their real debt level in surveys, we do not present regression analysis using these self-reported debt levels. 
average individual-level balance across all accounts that have gone to collection or were closed with balances is $\$ 2,450$ (s.d. $\$ 6,642$ ). The above balances are widely dispersed (as indicated by their large standard errors), so our analysis below focuses on log-transformed values: the natural logarithm of the balances plus $\$ 1$. None of the results reported change qualitatively when we use non-transformed balance values.

Individual credit reports allow us to see whether an individual is credit constrained with respect to his or her revolving accounts, and whether this affects choices made in the field experiment. In our sample, the average level of credit utilization is 23.8 percent (s.d. 34.8 percent), and the average revolving credit limit is $\$ 5,615$ (s.d. $\$ 12,896)$. Forty-seven percent of the participants cannot currently borrow, either because they have no current access to credit or because they have hit the credit limit on their credit cards. Taking those people into account, the average individual in the sample has access to $\$ 4,488$ (s.d $\$ 12,135$ ) in immediate funds from revolving accounts.

The above credit report information, in addition to an individual's payment history, is combined in the Fair Issac Corporation (FICO) credit score. The FICO score calculates individual credit risk and assigns it a value ranging from 300 to 850 (where a higher number means a lower risk). Not every participant had a FICO score, due either to insufficiently long or nonexistent credit history. In our sample, 23 percent of the participants were unscored. For scored individuals, the mean FICO score was 623 (s.d 83), which is below the U.S. average of $678^{16}$.

\section{III.2. Field experiment to elicit time preferences}

In order to elicit individual time preferences, we conducted choice experiments in which participants were asked to choose between a smaller reward at time $t$ and a larger reward at time $t+\tau>t$. Our methodology is similar to existing processes for eliciting time preferences [for examples, see Harrison et al. (2002); McClure et al. (2004); and Dohmen et al. (2006)]. For three different time frames, participants choose between receiving $\$ 80$ in the future $(t+\tau)$ and smaller amounts nearer to the present $(t)$. In the first set of choices, $t$ is the present (or zero) and $\tau$ is

\footnotetext{
16 From www.experian.com, 8/4/2006.
} 
equal to one month in the future. In the second set of choices, $t$ is the present and $\tau$ is six months in the future. In the third set of choices, both options are in the future: $t$ is in six months and $\tau$ is one month; that is, $t+\tau$ is seven months (see the appendix for the choice sets and a discussion of censoring issues).

Subjects were guided through the details of the choice sets by the same experimenter, assuring that the experimental design was explained to each participant in the same way and that they understood the process. Participants were also fully informed about the method of payment. In order to provide an incentive for the truthful revelation of preferences, some individuals' choices became effective. A lottery ticket determined which choice, if any, would be effective for a given individual. Payments to participants were guaranteed by the Federal Reserve Bank of Boston, and were made by money order. In order to keep transaction costs constant between rewards in the present and in the future, we mimicked a front-end-delay design (for example, Harrison et al., 2005; Holcomb and Nelson, 1992). All rewards were sent by mail; the letters were either mailed the day the experiment took place or in one, six, or seven months-depending on the winning participant's choice. ${ }^{17}$

The choices made in the three time frames allow us to capture individual time preferences. By analyzing the point at which a participant switches from preferring the sooner but smaller payment to preferring the later but larger payment, we can develop measures of their individual discount parameters. ${ }^{18}$ We measure individual discount parameters in two

\footnotetext{
${ }_{17}$ In an accompanying survey, individuals were asked whether they planned to move any time in the next seven months. Moving might present a potential confound for measuring impatience, as movers might question the likelihood that their mail would be forwarded to their new address in a timely manner. Movers might therefore prefer payments in the present for logistical reasons and not for reasons related to their underlying time preference. Around 31 percent of respondents did plan to move in the upcoming seven months $(n=143)$. Movers and non-movers exhibit no systematic differences in their discount rates. Including individual moving expectations in our regression analysis does not influence the results.

18 Seventeen individuals, representing 11 percent of our sample participants, do not exhibit a unique switching point in one or more of the choice sets. These individuals do not display systematic observable differences compared to those that do have a unique switching point. In the paper's main analysis, we focus on individuals who exhibit one unique switching point but including individuals with multiple switching points in our regression analysis (by taking their first switching point) does not qualitatively change our results (see section IV.4).
} 
ways. First, we assume a standard model of exponential discounting (wherein present bias parameter, $\beta$, equals one), and calculate an individual's exponential discount factor, $\overline{\delta_{\text {exp }}}$, by averaging an individual's discount factors across the three time frames. Second, we allow for dynamic inconsistency (wherein present bias parameter, $\beta$, may be less than one), and calculate an individual's long run discount factor $\overline{\delta_{h y p}}$ and present bias parameter $\bar{\beta}$ by averaging measures of $\beta$ and $\delta_{h y p}$ obtained through systems of equations. For a detailed explanation of our procedure for calculating discount parameters please see the appendix.

The estimated discount parameters from the standard exponential model (presented in Panel A in Table A.1 in the appendix) reveal two characteristics that are particularly important for this paper. First, participants exhibit monthly exponential discount factors of $\overline{\delta_{\exp }}=0.903$, which translate into an annual discount rate of around 240 percent. This discount factor may seem low but it is in line with previous research, which tends to find low discount factors in experimental studies (see Frederick, Loewenstein, and O'Donoghue, 2002). Second, individual exponential discount factors do not remain constant over time, but differ significantly between the three time frames. Consistent with other studies that measure time preferences (see Frederick, Loewenstein, and O'Donoghue, 2002), individuals are significantly more impatient in shorter time frames $(\mathrm{p}<.001, \mathrm{t}$-test $)$ and when the present is involved $(\mathrm{p}<.01, \mathrm{t}$-test $) .{ }^{19}$

If we measure a quasi-hyperbolic model, the calculated values show that individuals have an average long-run discount factor of around $\overline{\delta_{h y p}}=0.935$, and exhibit an average present-bias parameter of $\bar{\beta}=0.924$. (presented in Panel B in Table A.1 in the appendix).

The detailed nature of our available credit data allows us to examine several concerns with respect to the measured impatience parameters. As our objective is to test the hypothesis that individual heterogeneity in impatience leads to differences in credit behavior, we must

19 The first test compares the estimated exponential discount factors obtained from the choice set $(t=0, \tau=$ 1 month) with those obtained from the set ( $t=0, \tau=6$ months). The second test compares the estimated exponential discount factors from the set $(t=0, \tau=1$ month) with those obtained from the choice set $(t=$ 6 months, $\tau=1$ month). Among the study's participants, around 22 percent exhibit strictly increasing discount factors over both comparisons. 
account for two possible confounds: first, that credit availability (and constraints) might drive field experimental behavior; and second, that experience using credit changes an individual's degree of impatience, leading to a higher preference for receiving present payments. As discussed below, the data do not provide support for either one of these possibilities.

With respect to the first issue, our available credit data permit us to know precisely how much participants are still able to borrow on revolving accounts such as credit cards. We can correlate immediate credit availability to discount parameter measures. The correlation between the amount individuals can still borrow (in natural logarithm) and their exponential discount factor is small in size, and is not statistically significant $(r=0.10 ; p>0.25)$. Additionally, credit constraints are not correlated with either long-run discount factors or present bias parameters. Our results are robust to controlling for disposable income and a number of observable characteristics. Additionally our main conclusions are unchanged when controlling for individual credit availability (see section IV.4).

With respect to the second concern, if credit experience leads individuals to prefer immediate rewards, any correlation between credit behavior and impatience would be attributable only to some initial distribution of credit. Under this argument, we would expect that a variety of proxies for credit experience would be correlated with impatience. We find strong evidence against this argument. All of our discount parameter measures are unrelated to the likelihood that an individual will have sufficient credit experience to have a FICO score. These measures are also unrelated to the total number of loan accounts an individual has ever had, to the number of revolving credit card accounts an individual has ever had, and (as noted above) to an individual's credit limit. The fact that all of these indicators of credit experience are unrelated to measured impatience supports the claim that differential credit experience also cannot explain the heterogeneity in measured impatience and its correlation with credit behavior. 


\section{Analysis and Results}

This section analyzes the relationship between individual impatience and a person's credit behavior for three credit outcomes. We first analyze individual debt levels, and then investigate the value of past-due payments and balances on accounts in collection as proxies for delinquencies and defaults, respectively. Finally, we examine FICO scores as an aggregate measure of an individual's credit usage and behavior.

\section{IV.1. Impatience and debt level}

The following section attempts to elaborate on the empirical relationship between impatience and borrowing. Table 2 reports the relationships between impatience and individual debt levels (both active account debt and revolving debt alone). As debt is censored at zero, the table presents tobit models of the following form:

$$
D E B T_{i}=\alpha+\gamma_{1} I M P A T I E N C E_{i}+\gamma_{2} X_{i}+\varepsilon_{i}
$$

$D E B T_{i}$ is the $\log$ of individual $i$ 's level of debt. IMPATIENCE $E_{i}$ is a measure of individual impatience, measured as either an individual's exponential discount factor, $\overline{\delta_{\text {exp }}}$, or quasihyperbolic discounting parameters, $\bar{\beta}$ and $\overline{\delta_{h y p}}$. The vector $X_{i}$ reflects individual control variables, such as age, gender, race, and education. We also control for an individual's financial situation by entering disposable income and the number of dependents filed on annual tax returns in the regression. The models in Table 2 are based on the 138 observations for participants in the study who display unique switching points in the payment choice sets.

Panel A of the table presents tobit regression results for equation (1) where $D E B T_{i}$ is the natural logarithm of the level of total balances on all active accounts. The results indicate, that individuals with lower average exponential discount factors do not appear to have significantly higher active account balances. Specifying the functional form of discounting as quasihyperbolic in columns (3) and (4) shows, however, that while individuals' long-run discount 
factors, $\overline{\delta_{h y p}}$, cannot explain differences in account balances, present bias, $\bar{\beta}$, does appear to determine active account debt levels. In line with the behavioral hypothesis, controlling for personal characteristics, a higher present bias (lower $\bar{\beta}$ ), is associated with higher active account balances, with an implied elasticity of $-7.7(\mathrm{p}<.10)$. That is, a 1 percent increase in parameter $\bar{\beta}$ is associated with an almost 8 percent decline in active account balances.

This result (and the results which follow) is robust to the addition of socio-demographic controls (see Table A.2 in the appendix). This is consistent with the result that time preferences are largely independent of socio-demographic variables. ${ }^{20}$

Panel B of Table 2 reports on the specific relationship between impatience and revolving balances. The results are similar to the results for total balances on active accounts. The average exponential discount factor plays no explanatory role in the determination of revolving debt levels. Also, when discounting is structured as quasi-hyperbolic, the long-run discount factor, $\overline{\delta_{h y p}}$, exhibits no relationship to revolving balance levels. However, as expected, higher presenttime bias-lower $\bar{\beta}$-leads to significantly higher revolving balances; the implied elasticity is around -10.7 $(\mathrm{p}<.05)$, slightly stronger than the effect for active account balances. The difference in $\bar{\beta}$ elasticities between revolving and active account balances offers some support to the conclusion that revolving balances are affected more by present-time bias than are other account balances, but the difference is not statistically significant.

In sum, impatience is associated with higher debt levels, but the structure of individual time preferences is of critical importance. Lower long-run discount factors $\left(\overline{\delta_{h y p}}\right)$ are unrelated to active debt balances. This result is similar to Harrison, Morten, and Williams (2002), who also do not find a correlation between long-run discount factors and whether people carry debt. In our study, the decision of how much to borrow is driven by present-time bias $(\bar{\beta})$. Individuals

${ }^{20}$ With the exception of disposable income, which has a slight positive correlation with present-bias factors, demographics are independent of time preferences. Results can be obtained from the authors on request. 
with higher present-time bias borrow more on active accounts, particularly on revolving accounts such as credit cards. ${ }^{21}$

In the next section, we examine how impatience affects debt servicing, as reflected in delinquencies and defaults.

\section{IV.2. Impatience, delinquencies, and defaults}

Our measure of delinquency is the sum of past-due payments on active accounts for a given individual. Our measure of default is the sum of accounts in collection and closed accounts that still have balances. ${ }^{22}$ Table 3 presents tobit results for the following regressions:

$$
\begin{aligned}
& \operatorname{DELINQ}_{i}=\alpha+\gamma_{1} \text { IMPATIENCE }_{i}+\gamma_{2} X_{i}+\varepsilon_{i} \\
& \text { DEFAULT }_{i}=\alpha+\gamma_{1} \text { IMPATIENCE }_{i}+\gamma_{2} X_{i}+\varepsilon_{i} .
\end{aligned}
$$

As in previous models, IMPATIENCE $E_{i}$ is one of the two measures of impatience, and the $X_{i}$ are individual characteristics. $D E L I N Q_{i}$ and $D E F A U L T_{i}$ are individual i's levels in natural logarithms for the delinquency and default measures explained above.

Panel A of Table 3 presents results exploring the relationship between the log level of past-due payments on active accounts (installment and revolving accounts) and individual

${ }^{21}$ Though balances listed on credit reports are point-in-time measures, there is evidence that our debt measures closely reflect revolving balances and not convenience charges. In a companion survey, we asked individuals to report their credit card payment habits ( $\mathrm{n}=52$ cardholders). Controlling for demographics, more present-biased individuals are significantly more likely to make lower credit card payments (the minimum payment or less), leaving a larger portion of each bill as revolving balances. Additionally, controlling for demographics, individuals who regularly make lower payments have significantly higher revolving balances, approximately $\$ 2,500$ higher $(\mathrm{p}<.01)$, on their credit reports.

${ }^{22} \mathrm{~A}$ small portion of closed accounts may be receiving payment through organized payment plans and so may not be in default. Our analysis shows that more than 90 percent of closed accounts among the survey participants show some past due payment. Additionally, the median delinquency is around 75 percent of the account balance value. We take this as an indication that closed account balances are generally defaulted upon. 
impatience. ${ }^{23}$ Controlling for a variety of socio-demographic variables including disposable income, we find that individuals with lower average exponential discount factors, $\overline{\delta_{\text {exp }}}$, have significantly higher delinquencies. The control variables include a variable for the amount of outstanding balances on active accounts in order to capture the fact that individuals with very low balances will mechanically have very low delinquencies. The implied elasticity of -18 ( $\mathrm{p}<$ .10) shows a sizeable effect of small changes in impatience on past-due payment values. As we add structure to time discounting, we can explore whether the repayment decision is motivated by the same structural parameters as the initial borrowing decision. Higher present-time biaslower $\bar{\beta}$-is not associated with higher delinquencies. The long-run discount factor, $\overline{\delta_{h y p}}$, however, is negatively correlated with past-due payments. With an implied elasticity of -19.6 (p $<.10)$, individuals with lower $\overline{\delta_{\text {hyp }}}$ have significantly higher delinquencies.

Given that impatience in general, and the long-run discount factor in particular, play a role in determining delinquencies, Panel B in Table 3 explores delinquency's logical extension: default. We would expect similar results across regression equations (3) and (4), and this is largely confirmed by the data. Lower average exponential discount factors are associated with significant increases in the amount of defaulted debt. A one percent reduction in the exponential discount factor, $\overline{\delta_{\text {exp }}}$, coincides with a 15.9 percent increase in defaults $(\mathrm{p}<.01)$. A quasi-hyperbolic discounting structure indicates that, as posited in the previous section, balances on defaulted, inactive accounts are not determined by present bias, $\bar{\beta}$. Lower longrun discount factors, $\overline{\delta_{h y p}}$, however, are associated with significant increases in defaulted account balances; the implied elasticity is $-16(p<.01)$. In distinct contrast to borrowing decisions, which appear to be driven by present-time bias, repayment and default decisions seem to be driven by differences in long-run discounting. Individuals with lower $\overline{\delta_{h y p}}$ have markedly higher delinquent and defaulted account balances.

\footnotetext{
${ }^{23}$ Including past-due balances on closed accounts does not change the results qualitatively (if anything, it makes them more pronounced). By including closed accounts, however, delinquencies and defaults become confused, as most of the balance on a closed account is generally past due.
} 
The effect of impatience on delinquencies and defaults is not only reflected in the amount that is delinquent or in default. Exponential discount factors and long-run discount factors are also strongly associated with binary indicators for whether or not an individual has any delinquent balances or any defaulted balances. Controlling for demographics, individuals with lower exponential or long-run discount factors are significantly more likely to have a delinquent balance and are more likely to have a defaulted account balance.

In sum, individuals' present bias, $\bar{\beta}$, is not correlated with individual's repayment behavior, while the long-run discount factor, $\overline{\delta_{h y p}}$, seem to be important for the decision to service one's debt. Lower long-run discount factors lead to higher amounts that are delinquent and in default.

\section{IV.3. Impatience and FICO scores}

Table 4 reports the relationship between an individual's impatience and his or her FICO score. The table presents results from Ordinary Least Square (OLS) models of the following basic specification:

$$
\text { FICO }_{i}=\alpha+\gamma_{1} I M P A T I E N C E_{i}+\gamma_{2} X_{i}+\varepsilon_{i}
$$

where $\mathrm{FICO}_{i}$ is equal to individual i's FICO score and, as before, IMPATIENCE ${ }_{i}$ is one of the two measures of impatience, and the $X_{i}$ are individual characteristics. The models in Table 4 are based on the 105 observations for participants in the study who have FICO scores, ${ }^{24}$ and who display unique switching points in the payment choice sets.

In Table 4, columns (1) and (2) present regression results for specifications where $\overline{\delta_{\text {exp }}}$ is the impatience measure. The results show that people with lower discount factors have lower credit scores. The observed relationship is quite substantial, with an implied elasticity between

\footnotetext{
${ }^{24}$ Individuals who do not have a FICO score do not have different exponential discount factors than individuals with a credit score (0.904 versus $0.902 ; p<0.95$ in a $t$-test). However, they are younger and have lower income.
} 
$0.28(\mathrm{p}<.05)$ and $0.32(\mathrm{p}<.01)$, depending on the specification used. In other words, a decrease in the exponential discount factor by 1 percent is associated with a lower credit score of around one-third of 1 percent.

Columns (3) and (4) present the results of specifications obtained by allowing preferences to be quasi-hyperbolic. The results show that a lower long-run discount factor,

$\overline{\delta_{h y p}}$, is associated with lower credit scores. The parameter for present-bias, $\bar{\beta}$, however, is not significantly correlated with FICO scores. The addition of socio-demographic controls yields similar results for these two variables, confirming that more impatient individuals have lower credit scores, while also indicating that individuals who exhibit increasing discount factors over time do not have significantly different FICO scores than time-consistent individuals.

As an aggregate predictor of individual credit behavior, the results for FICO scores show that impatience has a significant influence on individual credit outcomes. Controlling for disposable income and other socio-demographic characteristics, individuals who exhibit lower long-run discount factors have lower scores. The results also suggest that individuals who display dynamic inconsistency do not have lower credit scores than those who are time consistent.

\section{IV.4. Robustness tests}

In this section, we test how robust the results are to changes in calculating impatience, to restricting the sample, and to controlling for credit limits. We also examine whether our measured time preferences can explain differences in credit behavior one year after individual time preferences were elicited.

As discussed in section III.2, we calculate the structure of individual time preferences based on specific assumptions. Three tests (presented in Panels A-C of Table 5) analyze whether the results are robust to changes in those assumptions: (1) we do not assume any structure on individual choices and instead simply count the number of patient $(\$ 80)$ choices; (2) instead of calculating a quasi-hyperbolic structural form, we create individual dummies in order to characterize whether a person exhibits increasing or decreasing discount factors, 
similar to Dohmen et al. (2006); and (3) we calculate individual $\bar{\beta}$ and $\overline{\delta_{h y p}}$ without restricting $\bar{\beta}$ to be $\leq 1$. For details of the calculations, see the appendix. In all three of these tests, the main conclusions of the previous analysis are robust to the alternative measures of impatience.

Table 5 shows three other robustness tests related to the sample restrictions. Panel D shows the relationship between impatience and credit behavior if the sample is restricted to individuals with complete information on all control variables. The main results do not change appreciably. Panel E shows the results if we include individuals who exhibit multiple switching points. For these individuals, we assume that their first switching point reveals their discount factor, and create a dummy variable which is equal to one if an individual does not exhibit an unique switching point. As expected, the estimation becomes less precise, but the qualitative results hold.

Panel $\mathrm{F}$ tests whether the results are robust to taking credit constraints into account. As noted above, credit reports include information on an individual's credit limit. Including the natural logarithm of an individual's credit limit as a control variable does not qualitatively change the results.

One potential criticism of our experimental design could be that very short-run income and asset conditions, unobservable to the experimenter, could be driving results. A particularly recent negative or positive income shock may be absent from the previous year's tax return, but the consequences of this shock may already be affecting an individual's credit report. These same conditions might also influence an individual's choices. If shocks are short-lived, and individual credit reports are changeable over time ${ }^{25}$, we would expect that the correlations between initial measures of impatience and credit behavior would disappear over time. As part of our experiment, individuals consent to having a second credit report obtained one year from their original report date. Contrary to the above hypothesis, the results obtained from analyzing the second year of data are largely similar to those obtained from analyzing the first year. Controlling for individual characteristics, FICO scores and default levels remain significantly

\footnotetext{
${ }^{25}$ Professional credit counselors suggest that six months of positive credit behavior can increase an individual's FICO score anywhere from 20 to 50 points.
} 
correlated with long-run discount factors. Delinquent payment levels remain negatively correlated with long-run discount factors, though not significantly so. Balances on active accounts retain a significant negative correlation with present-biased behavior. Revolving balances remain negatively correlated with present bias, though not significantly so. Despite these similarities, there are some changes in the results. $\overline{\delta_{h y p}}$ is significantly positively correlated with debt levels, and $\bar{\beta}$ has a significant positive correlation with past due accounts. These changes may be associated with income, asset, or behavioral changes for which we cannot control. Overall, we believe the second-year evidence, presented in Panel G of Table 5, lends weight to our existing results.

\section{Discussion}

The results indicate that present bias affects only the decision to borrow, even though both decisions, borrowing today and defaulting today, entail immediate benefits and future costs. Defaulting is mainly influenced by $\delta$. According to the quasi-hyperbolic model, dynamic inconsistencies should matter in every decision involving the present.

As noted in our conceptual considerations, present bias can be thought of as the interplay between two separate cognitive decision-making systems: the affective system, which values immediate gratification and sharply discounts all future time periods; and the deliberative system, which makes long-run plans and displays higher discount factors (see McClure et al., 2004). The quasi-hyperbolic model does not elaborate on the variety of stimuli that could engage (or not engage) the affective system, which generates dynamic inconsistencies. It is likely that the affective system is activated by other stimuli beyond choices involving the present or close temporal proximity (see Loewenstein and O'Donoghue, 2004). In fact, a variety of marketing techniques are designed to stimulate the affective system in different ways. According to this view, not every decision that involves a trade-off between today and tomorrow is expected to be influenced in the same way by the affective system, and correspondingly by present bias. The response to a trade-off between today and tomorrow then 
depends on the degree of stimulus to the affective system. If, for example, the affective system remains unaffected in a decision involving the present period, a person may act more deliberately and closely follow his or her long-term plans.

We suggest that the affective system is stimulated differently (for example through marketing) in our two critical choice environments of borrowing and repaying. Borrowing may be highly subject to present bias, as marketers encourage consumers to focus on immediate gratification when spending and borrowing. In this vein, the type of payment itself may be important for the effect of present bias. Credit card spending and borrowing might be especially sensitive to dynamic inconsistency (meaning it might involve a high degree of stimulus to the affective system), as the instant benefits obtained and long-term costs incurred are psychologically much more disconnected than for other payment methods such as cash (for example, see Bar-Gill, 2004; Prelec and Loewenstein, 1998).

The decision to default on a repayment obligation, however, is very different from the initial borrowing decision. Whereas individuals are frequently targeted by marketing efforts encouraging them to borrow, they are never targeted by marketing efforts encouraging them to default. Indeed, credit-granting institutions want individuals to make the exact minimum payment, but not a lesser amount. ${ }^{26}$ There is no concerted effort on the part of marketers to activate the affective system when presenting individuals with a repayment decision. Second, in the individual's mind the act of repayment itself is expected to be more salient than the act of borrowing. Whereas borrowing, specifically on a credit card, buffers consumption and costs, repayment likely does not have this physical feature. Sitting down with a checkbook to pay an itemized credit card bill is a more salient experience than a rapidly executed credit card purchase. The context in which the repayment decision is made could likely leave the affective system unstimulated.

\footnotetext{
26 There is a growing literature analyzing how firms might want to exploit consumers who exhibit decision-making anomalies (see, for example., Xavier Gabaix and David Laibson, 2006).
} 
The results presented in this paper are in line with an extended quasi-hyperbolic model in which the affective system is more stimulated (for example, by marketers) during the decision to borrow, while the affective system is less stimulated in the decision to default.

\section{Conclusions}

This paper presents direct evidence on how impatience influences credit behavior. In a field experiment targeted at low-to-moderate income households, we measure individual time preferences and test whether heterogeneity in impatience can explain objectively observed credit behavior. As self-reported measures of debt and credit problems are problematic, we analyze objective information from individual credit reports and combine it with individual measures of impatience.

The results show that present biased individuals (lower $\beta$ ) have higher balances on their active accounts in general and on credit cards in particular. To our knowledge, this is the first paper using objective data to show directly that present bias leads to higher levels of borrowing. The dynamic inconsistency inherent to present-biased time preferences indicates that some of this borrowing may be suboptimal, given individuals' long-run plans. The conclusion that dynamic inconsistency plays a role in determining borrowing behavior contradicts the view that current income conditions are the driving force behind credit behavior.

The results also show that the decision to service accumulated debts is not affected by present bias, but is affected by the long-run discount factor. The lower an individual's long-run discount factor, $\delta$, the higher the probability that this person will have balances in collection and in past due status, and have a lower FICO score. Even though both decisions, borrowing today and defaulting today, entail immediate benefits and future costs, present bias appears to affect only the decision that pertains to borrowing. This result shows that models of dynamic inconsistency may inadequately account for the various stimuli that trigger an individual's affective system. It appears that the affective system responsible for present bias is triggered by the decision to borrow, but not by the decision to default. This result is plausible, since credit- 
granting firms have an incentive to activate the affective system in borrowing-choice settings, but would prefer consumers to be more deliberate when deciding whether or not to default.

The results of this paper do not address the question of where heterogeneity in individual time preferences originates. Impatient tendencies are quite stable over time, and in very early childhood heterogeneity in impatience is found to predict behavior in adolescence and adulthood (for example, see Eigsti et al., 2006; Mischel, Shoda, and Rodriquez, 1989). However, it is still unclear whether parts of an individual's time preferences are determined endogenously (Becker and Mulligan, 1997). Though we do show that credit experiences and the number of accounts held over one's lifetime are unrelated to time preferences, it is possible that single adverse incidents, such as credit problems and bankruptcy, could have influential effects on individual preferences. Future research should explore whether negative life experiences, such as those noted, do actually influence individual time preferences. 


\section{References}

Anderson, Steffen, Harrison, Glenn W., Lau, Morten I., and Rutstrom, Elisabet E. "Eliciting Risk and Time Preferences," Mimeo. Centre for Economic and Business Research, Copenhagen, 2005.

Ashraf, Nava, Karlan, Dean, and Yin, Wesley. "Tying Odysseus to the Mast: Evidence from a Commitment Savings Product in the Philippines." Quarterly Journal of Economics, 2006, 121(1), pp. 635-672.

Avery, Robert B., Bostic, Raphael W., Calem, Paul S., and Canner, Glenn G. "An Overview of Consumer Data and Credit Reporting." Federal Reserve Bulletin, 2003, 89, pp. 47-73.

Bar-Gill, Oren. "Seduction by Plastic." Northwestern University Law Review, 2004, 98(4), pp. 13731434.

Becker, Gary S. and Mulligan, Casey B. "The Endogenous Determination of Time Preferences." Quarterly Journal of Economics, 1997, 112 (August), pp. 729-758.

Benesch, Christine, Frey, Bruno S., and Stutzer, Alois. "TV Channels, Self Control and Happiness," Mimeo. University of Zurich, 2006.

Bernheim, Douglas B. and Rangel, Antonio. "Addiction and Cue-Triggered Decision Processes." American Economic Review, 2004, 94(5), pp. 1558-1590.

Bertaut, Carol and Haliassos, Michael. "Debt Revolvers for Self Control," Mimeo. Department of Economics, University of Cyprus, 2002.

Bertrand, Marianne, Mullainathan, Sendhil, and Shafir, Eldar. "A Behavioral-Economics View of Poverty." American Economic Review, Papers and Proceedings, 2004, 94(2), pp. 419-423.

Bettinger, Eric and Slonim, Robert. "Patience among Children," Mimeo. Case Western Reserve University, 2006.

Bucks, Brian, Kennickell, Arthur, and Moore, Kevin. "Recent Changes in U.S. Family Finances: Evidence from the 2001 and 2004 Survey of Consumer Finances." Federal Reserve Bulletin, 2006, 92 (February), pp. A1-A38.

Coller, Maribeth, Harrison, Glenn W., and Rutström, Elisabet E. "Does Everyone Have QuasiHyperbolic Preferences?" Mimeo. University of Central Florida, 2005.

Coller, Maribeth and Williams, Melonie B. "Eliciting Individual Discount Rates." Experimental Economics, 1999, 2, pp. 107-127.

DellaVigna, Stefano and Malmendier, Ulrike. "Paying Not to Go to the Gym." American Economic Review, 2006, 96(3), pp. 694-719.

DellaVigna, Stefano and Paserman, Daniele M. "Job Search and Impatience." Journal of Labor Economic, 2005, 23(3), pp. 527-588.

Dohmen, Thomas, Falk, Armin, Huffman, David, and Sunde, Uwe. "Dynamic Inconsistency Predicts Self-Control Problems in Humans," Mimeo. Institute for the Study of Labor (IZA), Bonn, Germany, 2006.

Eckel, Catherine C., Johnson, Cathleen, and Monmarquette, Claude. "Saving Decisions of the Working Poor: Short and Long-Term Horizons," in J. Carpenter, G. W. Harrison, and J. A. List, Field Experiments in Economics. Greenwich and London: JAI Press, 2005.

Eigsti, Inge-Marie; Zayas, Vivian; Mischel, Walter; Shoda, Yuichi; Ayduk, Ozlem; Dadlani, Mamta B.; Davidson, Matthew C.; Aber, J. Lawrence; and Casey, B. J. "Predicting Cognitive 
Control from Preschool to Late Adolescence and Young Adulthood." Psychological Science, 2006, 17(6), pp. 478-484.

Fang, Hamming and Silverman, Dan. "Time-Inconsistency and Welfare Program Participation: Evidence from the Nlsy," Mimeo. Yale University, 2006.

Fehr, Ernst. "The Economics of Impatience." Nature, 2002, 415, pp. 269-272.

Fischer, Irving. The Theory of Interest. London: The Macmillan Company, 1930.

Frederick, Shane; Loewenstein, George, and O'Donoghue, Ted. "Time Discounting and Time Preference: A Critical Review." Journal of Economic Literature, 2002, 40(2), pp. 351-401.

Fudenberg, Drew and Levine, David K. "A Dual Self Model of Impulse Control." American Economic Review, 2006, 96 (5), pp. 1449-1476.

Gabaix, Xavier and Laibson, David. "Shrouded Attributes, Consumer Myopia, and Information Suppression in Competitive Markets." Quarterly Journal of Economics, 2006, 121(2), pp. 505540.

Gross, David and Souleles, Nicholas. "Do Liquidity Constraints and Interest Rates Matter for Consumer Behavior? Evidence from Credit Card Data." Quarterly Journal of Economics, 2002, 117(1), pp. 149-185.

Gruber, Jonathan and Köszegi, Botond. "Is Addiction 'Rational'? Theory and Evidence." Quarterly Journal of Economics, 2001, 116(4), pp. 1261-1305.

Harrison, Glenn W.; Lau, Morten I.; Rutstrom, Elisabet E.; and Williams, Melonie B. "Eliciting Risk and Time Preferences Using Field Experiments: Some Methodological Issues," in J. Carpenter, G. W. Harrison, and J. A. List, Field Experiments in Economics. Greenwich and London: JAI Press, 2005.

Harrison, Glenn W.; Lau, Morten I., and Williams, Melonie B. "Estimating Individual Discount Rates in Denmark: A Field Experiment." American Economic Review, 2002, 92(5), pp. 16061617.

Holcomb, James H. and Nelson, Paul S. "Another Experimental Look at Individual Time Preference." Rationality and Society, 1992, 4(2), pp. 199-220.

Kennickell, Arthur B.; Starr-McCluer, Martha; and Sundén, Annika E. "Family Finance in the U.S.: Recent Evidence from the Survey of Consumer Finances." Federal Reserve Bulletin, 1997, 83(1), pp. 1-24.

Laibson, David. "Golden Eggs and Hyperbolic Discounting." Quarterly Journal of Economics, 1997, 112(2), pp. 443-477.

Laibson, David, Repetto, Andrea, and Tobacman, Jeremy. "A Debt Puzzle," in P. Aghion, R. Frydman, J. Stiglitz, and M. Woodford, Knowledge, Information and Expectations in Modern Economics: In Honor of Edmund S. Phelps. Princeton: Princeton University Press, 2003, 228266.

. "Estimating Discount Functions with Consumption Choices over the Lifecycle," Mimeo. Harvard University, 2005.

Loewenstein, George and O'Donoghue, Ted. "Animal Spirit: Affective and Deliberative Processes in Economic Behavior," Mimeo. Carnegie Mellon University, 2004.

McClure, Samuel, Laibson, David, Loewenstein, George, and Cohen, Jonathan. "Separate Neural Systems Value Immediate and Delayed Monetary Rewards." Science, 2004, 306, pp. 503-507. 
Mischel, Walter, Shoda, Yuichi, and Rodriquez, Monica L. "Delay of Gratification in Children." Science, 1989, 244(4907), pp. 933-938.

Munasinghe, Lalith and Sicherman, Nachum. "Why Do Dancers Smoke? Smoking, Time Preference, and Wage Dynamics." Eastern Economic Journal, 2006, 32 (4), pp. 595-616.

O'Donoghue, Ted and Rabin, Matthew. "Doing It Now or Later." American Economic Review, 1999, 89(1), pp. 103-124. . "Incentives and Self Control," Mimeo. University of California at Berkeley, 2005.

Phelps, Edmund S. and Pollak, Robert A. "On Second-Best National Saving and GameEquilibrium Growth." Review of Economic Studies, 1968, 35, pp. 185-199.

Prelec, Drazen and Loewenstein, George. "The Red and the Black: Mental Accounting of Savings and Debt." Marketing Science, 1998, 17, pp. 4-28.

Rabin, Matthew. "Risk Aversion and Expected Utility Theory: A Calibration Theorem." Econometrica, 2000, 68(5), pp. 1281-1292.

Shapiro, Jesse. "Is There a Daily Discount Rate? Evidence from the Food Stamp Nutrition Cycle." Journal of Public Economics, 2005, 89(2-3), pp. 303-325.

Shefrin, Hersh M. and Thaler, Richard H. "The Behavioral Life-Cycle Hypothesis." Economic Inquiry, 1988, 26, pp. 609-643.

Shui, Haiyan and Ausubel, Lawrence M. "Time Inconsistency in the Credit Card Market," Mimeo. University of Maryland, 2005.

Staten, Michael S., Elliehausen, Gregory, and Lundquist, E. Christopher. "The Impact of Credit Counseling on Subsequent Borrower Credit Usage and Payment Behavior," Mimeo. Credit Research Center, Georgetown University, 2002.

Strotz, Robert H. "Myopia and Inconsistency in Dynamic Utility Maximization." Review of Economic Studies, 1956, 23, pp. 165-180.

Thaler, Richard H. "Irving Fisher: Modern Behavioral Economist." American Economic Review, Papers and Proceedings, 1997, 87(2), pp. 439-441.

Warren, Elizabeth. "The Over-Consumption Myth and Other Tales of Economics, Law, and Morality." Washington University Law Quarterly, 2004, 82, pp. 1485-1511. 


\section{Tables and Figures}

Table 1: Summary Statistics

\begin{tabular}{lccc}
\hline & Mean & $\begin{array}{c}\text { Standard } \\
\text { Deviation }\end{array}$ & $\mathrm{N}$ \\
\hline Panel A: Socio-Demographics & & & \\
\hline Disposable Income & $\$ 17,384.96$ & $\$ 13,105.93$ & 155 \\
Income imputed (= 1) & 0.06 & 0.25 & 155 \\
Number of dependents & 0.47 & 0.82 & 155 \\
Number of dependents imputed (=1) & 0.06 & 0.25 & 155 \\
Age & 32.26 & 11.58 & 155 \\
Age imputed (=1) & 0.06 & 0.25 & 155 \\
Male (=1) & 0.33 & 0.47 & 155 \\
Black (=1) & 0.86 & 0.35 & 155 \\
Race imputed (=1) & 0.16 & 0.37 & 155 \\
College experience & 0.44 & 0.50 & 155 \\
Education imputed (=1) & 0.26 & 0.44 & 155 \\
\hline Panel B: Credit Behavior & & & \\
\hline FICO Score & 622.86 & 83.13 & 120 \\
Balance on All Active Accounts & $\$ 8,557.54$ & $\$ 20,697.01$ & 155 \\
Balance on Revolving Accounts & $\$ 1,160.97$ & $\$ 2,328.78$ & 155 \\
Past Due Balances on All Accounts & $\$ 43.51$ & $\$ 203.62$ & 155 \\
Collection and Closed Account & $\$ 2,450.24$ & $\$ 6,642.30$ & 155 \\
Balances & $\$ 5,615.36$ & $\$ 12,896.94$ & 155 \\
Revolving Credit Limit & &
\end{tabular}

Notes: Statistics calculated from all 155 valid experiment participants, regardless of time preferences 
Table 2: Impatience and Debt Levels

\begin{tabular}{|c|c|c|c|c|}
\hline & $(1)$ & $(2)$ & (3) & (4) \\
\hline \multicolumn{5}{|c|}{ Panel A: Dependent variable: $\ln ($ Total active account balance) } \\
\hline$\overline{\delta_{\exp }}$ & $\begin{array}{c}1.29 \\
(6.17)\end{array}$ & $\begin{array}{l}-2.29 \\
(5.70)\end{array}$ & & \\
\hline $\bar{\beta}$ & & & $\begin{array}{l}-4.11 \\
(4.71)\end{array}$ & $\begin{array}{c}-7.70 \\
(4.43)(*)\end{array}$ \\
\hline$\overline{\delta_{\text {hyp }}}$ & & & $\begin{array}{r}5.90 \\
(6.57) \\
\end{array}$ & $\begin{array}{c}2.81 \\
(6.02) \\
\end{array}$ \\
\hline \multicolumn{5}{|c|}{ Panel B: Dependent Variable: $\ln$ (Balance on revolving accounts) } \\
\hline$\overline{\delta_{\text {exp }}}$ & $\begin{array}{c}2.24 \\
(6.54)\end{array}$ & $\begin{array}{l}-0.43 \\
(6.14)\end{array}$ & & \\
\hline $\bar{\beta}$ & & & $\begin{array}{l}-7.95 \\
(4.81)\end{array}$ & $\begin{array}{l}-11.57 \\
(4.61)^{*}\end{array}$ \\
\hline$\overline{\delta_{h y p}}$ & & & $\begin{array}{c}8.99 \\
(7.11) \\
\end{array}$ & $\begin{array}{r}6.82 \\
(6.48) \\
\end{array}$ \\
\hline Control Variables & No & Yes & No & Yes \\
\hline $\mathrm{N}$ & 138 & 138 & 138 & 138 \\
\hline
\end{tabular}

Notes: Tobit regressions. Standard errors in parentheses. Control variables include $\ln ($ disposable income), number of dependents, age, gender, race, college experience, and dummies for imputed income, age, gender, race, and education. To see the effects of the control variables, the full estimation of column (4) is presented in Table A.2 in the appendix.

Level of significance: ${ }^{(*)} p<0.1, * p<0.05, * * p<0.01$ 
Table 3: Impatience, Delinquencies and Defaults

\begin{tabular}{|c|c|c|c|c|}
\hline & (1) & $(2)$ & (3) & (4) \\
\hline \multicolumn{5}{|c|}{ Panel A: Dependent variable: $\ln$ (Past Due Balances on All Accounts) } \\
\hline$\overline{\delta_{\exp }}$ & $\begin{array}{c}-19.68 \\
(10.84)(*)\end{array}$ & $\begin{array}{c}-19.98 \\
(10.56)(*)\end{array}$ & & \\
\hline $\bar{\beta}$ & & & $\begin{array}{c}-5.75 \\
(8.67)\end{array}$ & $\begin{array}{c}-1.60 \\
(8.30)\end{array}$ \\
\hline$\overline{\delta_{\text {hyp }}}$ & & & $\begin{array}{c}-18.14 \\
(10.90)(*) \\
\end{array}$ & $\begin{array}{c}-20.89 \\
(11.09)(*) \\
\end{array}$ \\
\hline \multicolumn{5}{|c|}{ Panel B: Dependent Variable: $\ln$ (Collection and Closed Account Balances) } \\
\hline$\overline{\delta_{\exp }}$ & $\begin{array}{c}-16.39 \\
(5.77)^{* *}\end{array}$ & $\begin{array}{c}-17.66 \\
(5.75)^{* *}\end{array}$ & & \\
\hline $\bar{\beta}$ & & & $\begin{array}{l}-3.40 \\
(4.59)\end{array}$ & $\begin{array}{l}-4.32 \\
(4.60)\end{array}$ \\
\hline$\overline{\delta_{h y p}}$ & & & $\begin{array}{c}-15.78 \\
(6.00)^{* *}\end{array}$ & $\begin{array}{c}-17.09 \\
(5.97)^{* *}\end{array}$ \\
\hline Control Variables & No & Yes & No & Yes \\
\hline $\mathrm{N}$ & 138 & 138 & 138 & 138 \\
\hline
\end{tabular}

Notes: Tobit regressions. Standard errors in parentheses. Control variables include $\ln$ (disposable income), number of dependents, age, gender, race, college experience, and dummies for imputed income, age, gender, race, and education. To see the effects of the control variables, the full estimation of column (4) is presented in Table A.2 in the appendix.

Level of significance: ${ }^{(*)} p<0.1, * p<0.05,{ }^{* *} p<0.01$ 
Table 4: Impatience and FICO scores

\begin{tabular}{|c|c|c|c|c|}
\hline \multicolumn{5}{|c|}{ Dependent Variable: FICO Score } \\
\hline & $(1)$ & $(2)$ & (3) & (4) \\
\hline$\overline{\delta_{\text {exp }}}$ & $\begin{array}{c}221.37 \\
(76.35)^{* *}\end{array}$ & $\begin{array}{c}196.74 \\
(78.28) *\end{array}$ & & \\
\hline $\bar{\beta}$ & & & $\begin{array}{c}55.52 \\
(55.83)\end{array}$ & $\begin{array}{c}26.42 \\
(59.52)\end{array}$ \\
\hline$\overline{\delta_{h y p}}$ & & & $\begin{array}{c}228.69 \\
(77.29)^{* *}\end{array}$ & $\begin{array}{c}212.65 \\
(78.73)^{* *}\end{array}$ \\
\hline Control Variables & No & Yes & No & Yes \\
\hline $\mathrm{N}$ & 105 & 105 & 105 & 105 \\
\hline $\mathrm{R}^{2}$ & 0.07 & 0.18 & 0.07 & 0.18 \\
\hline
\end{tabular}

Notes: OLS regressions. Robust standard errors in parentheses. Control variables include $\ln ($ disposable income), number of dependents, age, gender, race, college experience, and dummies for imputed income, age, gender, race, and education. To see the effects of the control variables, the full estimation of column (4) is presented in Table A.2 in the appendix.

Level of significance: ${ }^{(*)} p<0.1, * p<0.05, * * p<0.01$ 
Table 5: Robustness tests

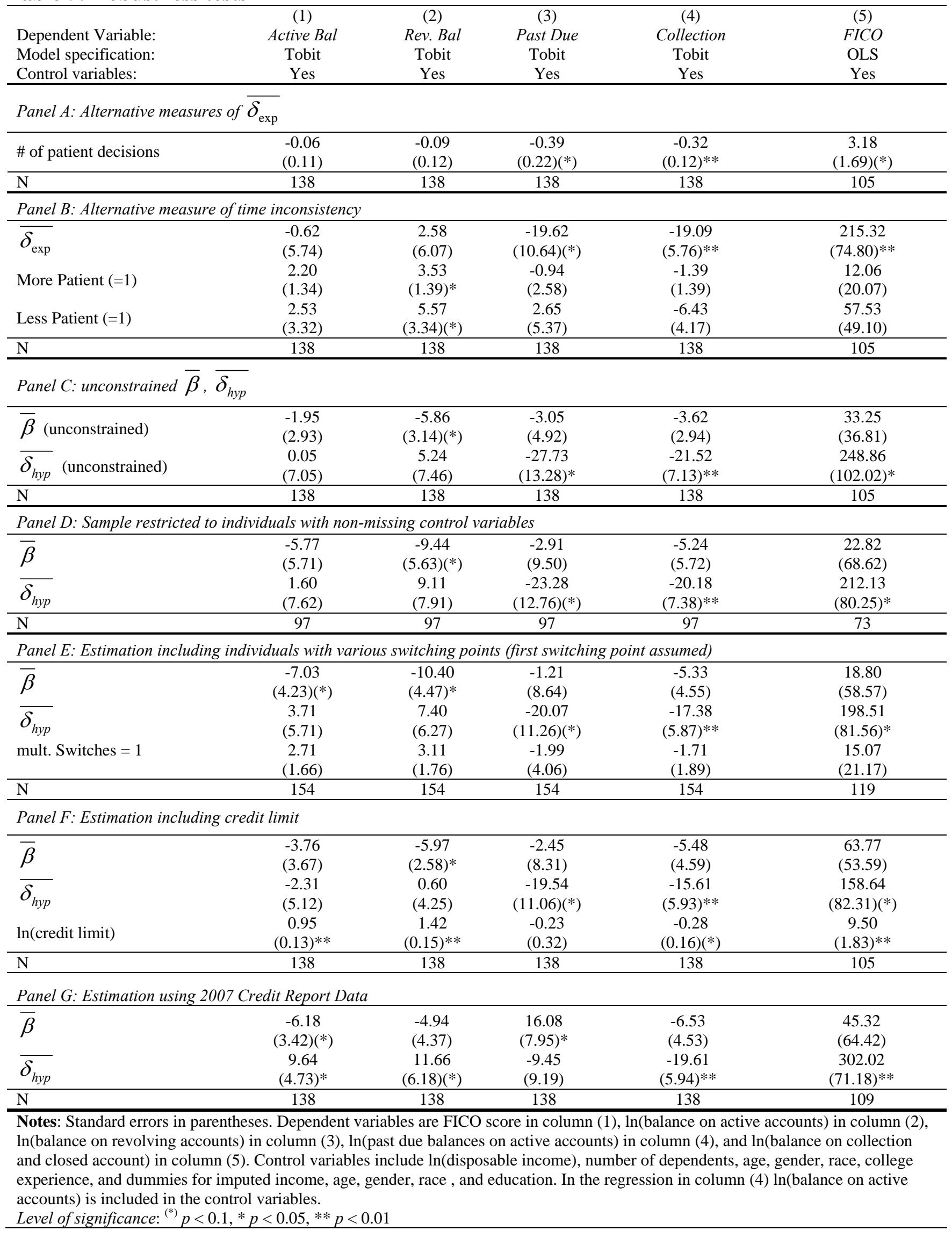




\section{Appendix}

Calculation of individual discount parameters

Our primary methodology for calculating individual discount parameters revolves around the quasi-hyperbolic form of discounting pioneered by Phelps and Pollack (1968) and further developed by Laibson (1997). The quasi-hyperbolic form is able to capture dynamic inconsistency and has standard exponential discounting as a special case. Under quasihyperbolic discounting, an individual is indifferent between a payout $Y_{t}$ in the present period $t$ and a future payout $Y_{t+\tau}$ in period $t+\tau$ when:

$$
u\left(Y_{t}\right)=\beta \delta^{\tau} u\left(Y_{t+\tau}\right),
$$

where $\beta$ represents the degree of present-bias and $\delta$ represents an individual's long run discount factor. When $\beta=1$, the quasi-hyperbolic model reduces to standard exponential discounting.

(1) Exponential discount factor. We calculate individual discount factors by assuming a standard exponential discounting structure $u\left(Y_{t}\right)=\delta_{\exp _{t, \tau}}^{\tau} u\left(Y_{t+\tau}\right)$, where $u\left(Y_{t}\right)$ is the utility of a monetary payment at time $t, \tau$ is the time delay for the bigger monetary payment, and $\delta_{\exp _{t, \tau}} \leq 1$ is the discount factor. In this case, the discount factor $\delta_{\exp _{t, \tau}}$ equates the utility from the sooner/smaller monetary payment and the utility from the later/larger monetary payment. For a given period $\tau, u(Y)$ is always discounted by the same factor $\delta_{\exp _{t, \tau}}$ (regardless of the value of $t$ ), leading to consistent preferences over time.

In the field experiment, each individual reveals the lowest immediate $Y_{t}$ for which $u\left(Y_{t}\right) \geq \delta_{\exp _{t, \tau}}^{\tau} u(80)$ for two different values of $\tau$. Let this lowest $Y_{t}$ be called $Y_{t}^{*}$. So, for example, if a participant prefers $\$ 70$ today over $\$ 80$ in a month and prefers $\$ 80$ in a month over $\$ 65$ today, we know that $u(70) \geq \delta_{\exp _{t, \tau}}^{1} u(80)$ and that $u(65) \leq \delta_{\exp _{t, \tau}}^{1} u(80)$. To calculate the discount factor, $\delta_{\exp _{t, \tau} \tau^{\prime}}$ we assume equal utility at the switching point from the immediate monetary reward, $Y_{t}$, to the later/larger payment, $\$ 80$. That is, at $Y_{t}^{*}, u\left(Y_{t}^{*}\right)=\delta_{\exp _{t, \tau}}^{\tau} u(80)$. We do not know the functional form of $u(\cdot)$, which translates monetary payments into utility. However, by assuming 
that $u(\cdot)$ does not change systematically over time, $u(0)=0$, and $u(\cdot)$ is at least locally linear, ${ }^{27}$ we can calculate $\delta_{\exp _{t, \tau}}^{\tau}=Y_{t}^{*} / 80$. We measure an individual's discount factor for all three time frames $\left(\delta_{\exp _{0,1}}, \delta_{\exp _{0,6}}, \delta_{\exp _{6,7}}\right)$. In our analysis, we use the average of these three measures as an independent variable, $\overline{\delta_{\text {exp }}}$, that estimates an individual's exponential discount factor.

(2) Quasi-hyperbolic discounting parameters. Our second measurement methodology allows for the possibility of dynamic inconsistency and creates measures for an individual's long-run discount factor $\overline{\delta_{h y p}}$ and present bias parameter $\bar{\beta}$ by averaging values obtained from systems of equations.

In the field experiment, we can calculate individual measures of $\beta$ and $\delta_{h y p}$ for the choices indicated across the today/one month and today/six months time frames. We call these measures $\beta_{1}$ and $\delta_{h y p_{1}}$. The same measures $\left(\beta_{2}, \delta_{h y p_{2}}\right)$ can also be obtained for the choices across the today/one month and six/seven months time frames.

Our measures for $\beta_{i}$ and $\delta_{h y p_{i}}(\mathrm{i}=1,2)$ are constructed cautiously. For each unique switching point in the today/six months and six months/seven months time frames, we take an upper and a lower bound for the response. We define these choices as $C_{\text {low }}$ and $C_{\text {high. }}$. For example, an individual may prefer $\$ 75$ in six months over $\$ 80$ in seven months and switch at the next choice, preferring $\$ 80$ in seven months over $\$ 70$ in six months. For this person there is a band of possible switching points, ranging from $\$ 70.01$ to $\$ 74.99$. The high and low ends of this band imply very different monthly discount factors.

In order to determine whether an individual is time inconsistent we develop a measure of time consistency based upon the initial choice made in the today/one month time frame. Using the implied discount factor from the initial choice, we create the response the individual should give in the other two choice sets if he or she is a time-consistent, exponential discounter. Similar to the above example, the initial choice is not taken literally as a single number but is

\footnotetext{
${ }^{27}$ For small changes in wealth, it is reasonable to assume that marginal utility from monetary outcomes is approximately linear (Rabin, 2000). For a critique of this assumption in measuring time preferences, see Anderson et al. (2005). According to this study, discount factors get significantly higher when taking risk preferences into account.
} 
taken as a range implying different discount factors and correspondingly different time consistent choices at the high and low end. We define the range of time-consistent choices in a given choice set as running from $T C_{\text {low }}$ to $T C_{\text {high }}$.

Comparing the two bands $\left[C_{\text {low }}, C_{h i g h}\right]$ and $\left[T C_{l o w}, T C_{h i g h}\right]$ for a particular choice set allows us to conservatively determine who is and who is not time inconsistent. Any individual for whom the entirety of $\left[C_{\text {low }}, C_{h i g h}\right]$ is not above $T C_{\text {high }}$ is considered to be time consistent, since this implies that his discount factor does not increase substantially over time. Individuals taken as time consistent are assigned $\beta_{i}=1$, and have $\delta_{h y p_{i}}$ calculated as the average of the two discount factors, $\delta_{\exp _{t, \tau}}$, for the choice sets in question.

Individuals who are time inconsistent, that is, individuals for whom the entirety of [Clow , $\left.C_{h i g h}\right]$ is above $T C_{h i g h}$, have their $\beta_{i}$ and $\delta_{h y p_{i}}$ calculated from a system of two equations with two unknowns. To begin, consider the two choice sets $[t, \tau]:[0,1]$ and $[0,6]$, that is, today/one month and today/six months. The resulting system of equations is then:

$\left(Y_{0,1}\right)=\beta_{1} \delta_{h y p_{1}}^{1}(80)$

and

$\left(Y_{0,6}\right)=\beta_{1} \delta_{\text {hyp }}^{6}(80)$,

where $\left(Y_{0,1}\right)$ and $\left(Y_{0,6}\right)$ are the switching points indicated in the choice sets $[0,1]$ and $[0,6]$ respectively. Dividing (A2) by (A1) we find that:

$$
\begin{aligned}
& \frac{\left(Y_{0,6}\right)}{\left(Y_{0,1}\right)}=\delta_{\text {hyp }}^{5}(80), \\
& \text { which gives }\left(\frac{\left(Y_{0,6}\right)}{80\left(Y_{0,1}\right)}\right)^{1 / 5}=\delta_{h y p_{1}} .
\end{aligned}
$$

Correspondingly, $\beta_{1}=\frac{\left(Y_{0,1}\right)}{\delta_{h y p_{1}}^{1}(80)}$.

In the two choice sets $[t, \tau]:[0,1]$ and $[6,7]$, the system of two equations is:

$$
\begin{aligned}
& \left(Y_{0,1}\right)=\beta_{\text {hyp }} \delta_{h y p_{2}}^{1}(80), \\
& \left(Y_{6,7}\right)=\delta_{h y p_{2}}^{1}(80)
\end{aligned}
$$


where $\left(Y_{0,1}\right)$ and $\left(Y_{6,7}\right)$ are the switching points indicated in the choice sets $[0,1]$ and $[6,7]$, respectively. Note that there is no term $\beta_{2}$ in equation $\mathrm{A} 4$. The individual has no present bias factor in choice sets involving two choices in the future. Dividing (A3) by (A4) we obtain: $\frac{\left(Y_{0,1}\right)}{\left(Y_{6,7}\right)}=\beta_{2}$ and $\frac{\left(Y_{0,1}\right)}{(80) \beta_{2}}=\delta_{h y p_{2}}$.

Taking the average of $\beta_{1}$ and $\beta_{2}$ yields the primary measure for present bias, $\bar{\beta}$, used in our regression analysis. Similarly we use the average of $\delta_{h y p_{1}}$ and $\delta_{h y p_{2}}$ to create $\overline{\delta_{h y p}}$, our primary measure of long-term discount factors.

\section{Further Measures Used for Robustness Checks}

Robustness checks presented in the Table 5 include relaxing the restrictions on $\beta_{i}$ and $\delta_{h y p_{i}}$. Firstly, we calculate every individual's $\beta_{i}$ and $\delta_{h y p_{i}}$ using the equations above, without a prior check for time consistency. Secondly, we allow individuals with multiple switching points in a choice set to enter the sample. For these individuals, we set $\left(Y_{t, \tau}\right)$ equal to the individual's first switching point and calculate time preference parameters, $\beta_{i}$ and $\delta_{h y p_{i}}$, using the more conservative approach (i.e., using a prior check for time consistency).

In one additional robustness check, we create dummy variables for individuals who clearly exhibit different exponential discount rates across different choice sets. An individual is considered to have MorePatient $=1$ if $\beta_{1}<1$ and $\beta_{2}<1$; that is, he or she shows present bias when comparing choice set $[0,1]$ to both choice sets [0,6] and [6,7]. MorePatient is set to zero for all other individuals. Additionally, a small number of individuals grow less patient when comparing choice set $[0,1]$ to choice sets $[0,6]$ and $[6,7]$. These individuals, for whom $\beta_{1}>1$ and $\beta_{2}>1$, are considered to have LessPatient $=1$. LessPatient is set to zero for all other individuals. The MorePatient and LessPatient dummies are included in regressions with the average exponential discount rate, $\overline{\delta_{\text {exp }}}$. 
Table A.1: Measures of impatience

Panel A: Exponential discount factor

$\overline{\delta_{\exp }}=0.903 \quad \delta_{\exp _{0,1}}=.867 \quad \delta_{\exp _{0,6}}=0.937 \quad \delta_{\exp _{6,7}}=0.905 \quad \mathrm{~N}=138$

Panel B: Quasi-hyperbolic functional forms

$\bar{\beta}=0.924 \quad \beta_{1}=0.927 \quad \beta_{2}=0.920 \quad \mathrm{~N}=139$

$\overline{\delta_{\text {hyp }}}=0.935 \quad \delta_{h y p_{1}}=0.945 \quad \delta_{\text {hyp }}=0.924 \quad \mathrm{~N}=139$

Notes: Monthly discount factors. See Section III.2 for a description of the calculation. 
Table A.2: Expanded Regressions
(1)
(2)
(3)
(4)
(5)

\begin{tabular}{|c|c|c|c|c|c|}
\hline Dependent Variable: & Active Bal & Rev. Bal & Past Due & Collection & FICO \\
\hline \multirow[t]{2}{*}{$\bar{\beta}$} & -7.70 & -11.57 & -1.60 & -4.32 & 26.42 \\
\hline & $(4.43)(*)$ & $(4.61)^{*}$ & (8.30) & $(4.60)$ & $(59.52)$ \\
\hline \multirow{2}{*}{$\overline{\delta_{h y p}}$} & 2.81 & 6.82 & -20.89 & -17.09 & 212.65 \\
\hline & $(6.02)$ & $(6.48)$ & $(11.09)(*)$ & $(5.97)^{* *}$ & $(78.73)^{* *}$ \\
\hline \multirow{2}{*}{$\begin{array}{l}\ln \text { (Balance on Active } \\
\text { Accts) }\end{array}$} & & & 1.31 & & \\
\hline & & & $(0.47)^{* *}$ & & \\
\hline \multirow[t]{2}{*}{ In (Disposable income) } & 2.62 & 2.57 & -0.73 & 0.95 & 5.33 \\
\hline & $(0.72)^{* *}$ & $(0.81)^{* *}$ & $(1.42)$ & $(0.71)$ & (9.33) \\
\hline \multirow{2}{*}{$\begin{array}{l}\text { Disposable income } \\
\text { imputed (= 1) }\end{array}$} & 22.23 & 25.50 & -8.57 & 8.30 & 93.47 \\
\hline & $(7.34)^{* *}$ & $(8.16)^{* *}$ & (14.39) & $(7.31)$ & $(96.51)$ \\
\hline \multirow[t]{2}{*}{ Number of dependents } & -0.65 & -0.86 & -0.93 & 0.00 & 4.38 \\
\hline & $(0.75)$ & $(0.79)$ & $(1.57)$ & $(0.79)$ & $(11.00)$ \\
\hline \multirow[t]{2}{*}{ Age } & 0.05 & 0.09 & -0.01 & -0.01 & 1.71 \\
\hline & $(0.05)$ & $(0.05)(*)$ & $(0.10)$ & $(0.05)$ & $(0.79)^{*}$ \\
\hline \multirow[t]{2}{*}{ Male (= 1) } & -2.83 & -2.87 & -1.32 & -0.76 & -0.10 \\
\hline & $(1.28)^{*}$ & $(1.36)^{*}$ & $(2.66)$ & $(1.32)$ & $(16.46)$ \\
\hline \multirow[t]{2}{*}{ Black (= 1) } & 0.67 & 0.07 & 1.35 & 3.08 & -43.71 \\
\hline & $(1.57)$ & $(1.64)$ & $(3.32)$ & $(1.72)(*)$ & $(27.15)$ \\
\hline \multirow[t]{2}{*}{ Race imputed (= 1) } & -0.85 & -2.27 & 1.88 & -1.75 & 27.65 \\
\hline & $(2.10)$ & $(2.25)$ & (3.79) & (2.19) & $(30.72)$ \\
\hline \multirow[t]{2}{*}{ College experience $(=1)$} & 0.50 & -0.81 & -5.05 & -0.31 & 20.18 \\
\hline & $(1.47)$ & $(1.56)$ & (3.15) & $(1.52)$ & $(20.44)$ \\
\hline \multirow[t]{2}{*}{ Education imputed (= 1) } & 0.95 & 0.79 & -1.81 & 2.05 & -4.26 \\
\hline & $(1.92)$ & (1.99) & $(3.44)$ & (1.99) & $(24.37)$ \\
\hline \multirow[t]{2}{*}{ Constant } & -18.14 & -20.83 & 13.62 & 10.88 & 308.49 \\
\hline & $(8.91)^{*}$ & $(9.50)^{*}$ & $(16.81)$ & $(8.96)$ & $(113.06)^{* *}$ \\
\hline $\mathrm{N}$ & 139 & 139 & 139 & 139 & 105 \\
\hline $\mathrm{R}^{2}$ or Pseudo $\mathrm{R}^{2}$ & 0.04 & 0.05 & 0.12 & 0.03 & 0.18 \\
\hline
\end{tabular}

Notes: Standard errors in parentheses. Dependent variables are FICO score in column (1), ln(balance on active accounts) in column (2), $\ln$ (balance on revolving accounts) in column (3), $\ln$ (past due balances on active accounts) in column (4), and ln(balance on collection and closed account) in column (5). Control variables for imputed number of dependents and imputed age dropped due to collinearity with imputed disposable income. Pseudo $\mathrm{R}^{2}$ calculated for tobit models, $\mathrm{R}^{2}$ calculated for ordinary least squares models.

Level of significance: $\left({ }^{*}\right) \mathrm{p}<0.10,{ }^{*} \mathrm{p}<0.05,{ }^{* *} \mathrm{p}<0.01$ 


\section{Decision Sheet}

Please indicate for each of the following 19 decisions, whether you would prefer the smaller payment in the near future or the bigger payment later. The number of your raffle ticket (none or 1 to 19), will indicate which decision you will be paid, if at all.

\begin{tabular}{|l|l|l|}
\hline & Option A (TODAY) & Option B (IN A MONTH) \\
\hline Decision (1) & $\square$ \$ 75 guaranteed today & $\square$ \$ 80 guaranteed in a month \\
\hline Decision (2) & $\square$ \$ 70 guaranteed today & $\square$ \$ 80 guaranteed in a month \\
\hline Decision (3) & $\square$ \$ 65 guaranteed today & $\square$ \$ 80 guaranteed in a month \\
\hline Decision (4) & $\square$ \$ 60 guaranteed today & $\square \$ 80$ guaranteed in a month \\
\hline Decision (5) & $\square$ \$ 50 guaranteed today & $\square \$ 80$ guaranteed in a month \\
\hline Decision (6) & $\square \$ 40$ guaranteed today & $\square \$ 80$ guaranteed in a month \\
\hline
\end{tabular}

\begin{tabular}{|l|l|l|} 
& Option A (TODAY) & Option B (IN 6 MONTHS) \\
\hline Decision (7) & $\square$ \$ 75 guaranteed today & $\square$ \$ 80 guaranteed in 6 months \\
\hline Decision (8) & $\square$ \$ 70 guaranteed today & $\square$ \$ 80 guaranteed in 6 months \\
\hline Decision (9) & $\square$ \$ 65 guaranteed today & $\square$ \$ 80 guaranteed in 6 months \\
\hline Decision (10) & $\square$ \$ 60 guaranteed today & $\square \$ 80$ guaranteed in 6 months \\
\hline Decision (11) & $\square$ \$ 50 guaranteed today & $\square \$ 80$ guaranteed in 6 months \\
\hline Decision (12) & $\square \$ 40$ guaranteed today & $\square \$ 80$ guaranteed in 6 months \\
\hline Decision (13) & $\square \$ 30$ guaranteed today & $\square \$ 80$ guaranteed in 6 months \\
\hline
\end{tabular}

\begin{tabular}{|c|c|c|}
\hline & Option A (IN 6 MONTHS) & Option B (IN 7 MONTHS) \\
\hline Decision (14) & $\square \$ 75$ guaranteed in 6 months & $\square \$ 80$ guaranteed in 7 months \\
\hline Decision (15) & $\square \$ 70$ guaranteed in 6 months & $\square$ \$ 80 guaranteed in 7 months \\
\hline Decision (16) & $\square$ \$ 65 guaranteed in 6 months & $\square$ \$ 80 guaranteed in 7 months \\
\hline Decision (17) & $\square$ \$ 60 guaranteed in 6 months & $\square \$ 80$ guaranteed in 7 months \\
\hline Decision (18) & $\square \$ 50$ guaranteed in 6 months & $\square \$ 80$ guaranteed in 7 months \\
\hline Decision (19) & $\square$ \$ 40 guaranteed in 6 months & $\square \$ 80$ guaranteed in 7 months \\
\hline
\end{tabular}




\section{Discussion of Choice Set Censoring}

Because of the nature of the choice sets employed, the participants are subject to two types of censoring. The first censoring is that individuals are limited by the available choice set; they may either accept every sooner but smaller payment offered or choose every later but larger payment. For the former behavior, the bounds of responses that we applied account for the possibility that such individuals would have accepted any sooner payment, down to one cent. For the latter, the bounds of responses account for the possibility that the individual would have accepted a payment one cent above the largest of the sooner payments offered.

The second type of censoring reflects the possibility that in the experiment individuals do not reveal their actual preferences for payments over different time horizons, but instead reveal their outside borrowing and investing opportunities (Coller and Williams, 1999). Two possible cases can be distinguished:

First, an individual may accept a sooner but smaller payment, because his or her investment opportunities outside the lab yield a return superior to that offered in the experiment. The choices we designed make it, however, very difficult for participants to find investment opportunities with better returns than the experiment. The very lowest rate an individual must beat with their investment opportunities is 14 percent per year. Therefore, outside investment opportunities are probably not driving the experimental responses.

Second, if an individual chooses to receive a later but larger payment, he or she may be able to borrow at better rates in the real world than at the experimentally-offered rate. As the lowest interest rate to beat is 14 percent, this is substantially easier for individuals to do. In fact, in our sample most individuals with revolving credit card accounts have not reached their credit limit and can still borrow on these accounts, which might have interest rates lower than 14 percent. Furthermore, 88 percent of study participants that responded to a question about nontraditional borrowing opportunities report having at least one friend or family member from whom they could borrow $\$ 100$ at an interest rate of zero $(n=127)$. Despite the ease of finding superior borrowing opportunities, individuals do not, as a rule, choose to receive every later but larger payment. Hence, outside borrowing opportunities are most likely not driving the experimental responses. 